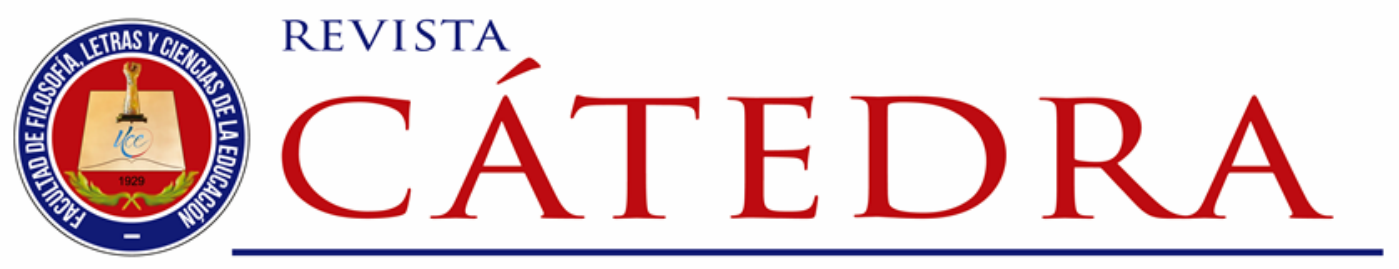

\title{
Aproximación al estado situacional de los derechos docentes en la década de gobierno correísta, Ecuador
}

\section{Approach to the situational state of the educational rights in the decade of correista government, Ecuador}

\author{
Oswaldo Haro-Jácome \\ Universidad Central del Ecuador, Quito, Ecuador \\ oharo@uce.edu.ec \\ https://orcid.org/0000-0001-6387-9591
}

Ana Chamorro-Morales

Universidad Central del Ecuador, Quito, Ecuador anabel0952@gmail.com

https://orcid.org/0000-0001-8741-8140

(Recibido: 20/10/2019; Aceptado: 30/10/2019; Versión final recibida: 08/01/2020)

Cita del artículo: Haro-Jácome, 0. y Chamorro-Morales, A. (2020). Aproximación al estado situacional de los derechos docentes en la década de gobierno correísta, Ecuador. Revista Cátedra, 3 (1), 116-135.

\section{Resumen}

El estudio analiza la situación de los derechos del profesorado ecuatoriano en los ámbitos laboral y gremial durante la década de gobierno correísta. Se trata de una investigación necesaria en la academia que recoge las apreciaciones de docentes pertenecientes al sector de servidores públicos regentados por el Estado. La pertinencia radica en la descripción de la disputa entre el magisterio organizado en su gremio, la Unión Nacional de Educadores (UNE), con el poder gubernamental liderado por el Eco. Rafael Correa (expresidente del Ecuador), durante la década 2007-2017. La investigación es fundamentalmente cualitativa, retrospectiva, transversal y descriptiva. El instrumento empírico es la encuesta aplicada a una población de 300 docentes en servicio, indagados durante el periodo lectivo 2017-2018. Complementariamente se utilizó entrevistas a profundidad aplicada a profesionales expertos en derechos humanos y participación ciudadana. Como resultados más sobresalientes se encontró que, mayoritariamente, los docentes perciben haber sido objeto

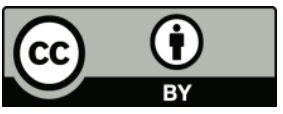


de vulneración en sus derechos, especialmente laborales, sindicales y de libertades civiles. Las afectaciones sistemáticas al magisterio, como sector profesional y a los docentes en particular, se produjeron por una acción política intencional planeada por el poder gubernamental. Los datos de campo también demuestran que pocos docentes aprecian haber sido beneficiados por el gobierno.

Palabras clave

Correísmo, derechos, docentes, Estado, política.

\section{Abstract}

The study analyzes the situation of the rights of Ecuadorian teachers in the labor and union spheres during the decade of correísta government. This is a necessary investigation in the academy, which includes the assessments of teachers belonging to the public servants sector run by the state. The relevance lies in the description of the dispute between the teachers organized in their guild, the National Union of Educators (UNE), with the governmental power led by the controversial Eco. Rafael Correa, during the 2007-2017 decade. The research is fundamentally qualitative, retrospective, transversal and descriptive. The empirical instrument is the survey applied to a population of 300 teachers in service, investigated during the 2017-2018 school period. In addition, in-depth interviews were applied to professional experts in human rights and citizen participation. As more outstanding results it was found that, mostly, teachers perceive having been subject to violation of their rights, especially labor, union and civil liberties. Systematic effects on teachers, as a professional sector and teachers in particular, were produced by an intentional political action planned by the power of the state. Field data also show that a few teachers appreciate having been benefited by the government.

\section{Keywords}

Correísmo, rights, teachers, state, politics.

\section{Introducción}

El análisis político en el Ecuador sobre el gobierno del Eco. Rafael Correa Delgado (20072017) desde su llegada al poder en enero de 2007, hasta su finalización en mayo de 2017, es muy polémico. Un sector político muy representativo defiende las acciones y prácticas del Correísmo; contrariamente otro sector importante también lo considera como represivo $\mathrm{y}$ anti-derechos sociales.

Durante la década correísta se ha probado reiteradamente que hubo represión social del Estado contra los movimientos sociales. La Mesa por la Verdad y la Justicia en febrero de 2019, "concluyó que el exmandatario y funcionarios de ese gobierno, usaron a la justicia para perseguir a opositores y criminalizar la protesta social” (El telégrafo, 2019, pág. 12). Precisamente el estudio es una aproximación a la realidad del gremio de docentes en el Ecuador, denominado Unión Nacional de Educadores (UNE). Justamente fue el discurso presidencial del Eco. Rafael Correa Delgado permanentemente pronunciado en las sabatinas ${ }^{1}$ y otros espacios políticos y las acciones judiciales, las formas más visibles de vulneración a los derechos humanos de gran parte de la población. Junto a los indígenas,

\footnotetext{
${ }^{1}$ Sabatinas: son los denominados enlaces ciudadanos de rendición de cuentas del gobierno correísta transmitidos por radio y televisión, los días sábados, desde el año 2007 hasta el año 2017.
} 
movimiento obrero, los ecologistas, uno de los sectores más afectados por la década denominada correísta fueron los docentes. Como ejemplos se pueden citar: incremento de la jornada laboral a 40 horas semanales con reducción de sueldos, ilegalización a la UNE, desconocimiento de los incentivos de jubilación, remociones forzadas a docentes, actividades complementarias absurdas que agobiaron al docente, tanto en la institución educativa, como en su hogar.

Las afectaciones descritas al magisterio ecuatoriano contradicen con corrientes humanistas que abogan por la permanente necesidad de progresar en la calidad de los sistemas educativos, con aporte vital del docente. Según McKinsey \& Company (2008), "la calidad de un sistema educativo tiene como techo la calidad de sus docentes” (pág. 15). Muchos países asiáticos están priorizando la formación docente de calidad y luego apoyan social y económicamente a la profesión, como factor de éxito del sistema social puesto que, al priorizar el bienestar docente, su labor se vuelve más eficaz y consecuentemente la educación supera las expectativas, es el "tradicional respeto por el docente" (McKinsey \& Company, 2008, pág. 15).

También, organismos multilaterales como la Organización de Naciones Unidas (ONU) y La Organización de las Naciones Unidas para la Educación, la Ciencia y la Cultura (UNESCO) han puesto en marcha acciones de reivindicación docente, evidenciadas en la Declaración de Incheon (2015), que en el cuarto Objetivo de Desarrollo Sostenible afirma:

(...) velaremos por que los docentes y educadores estén empoderados, sean debidamente contratados, reciban una buena formación, estén cualificados profesionalmente, motivados y apoyados dentro de sistemas que dispongan de recursos suficientes, que sean eficientes y que estén dirigidos de manera eficaz (pág. 8).

El propósito del presente estudio es explorar la situación de los derechos de los docentes y su sindicato, durante el periodo gubernamental del Eco. Rafael Correa Delgado se aborda las variables de derechos laborales docentes y derechos gremiales. El primer aspecto de la investigación se enfoca en la situación de derechos individuales del magisterio ecuatoriano con base con los convenios internacionales, mandatos constitucionales ecuatorianos, normativas y disposiciones vigentes en el período de estudio. El segundo aspecto describe la situación de la UNE, como el gremio docente de mayor incidencia en la defensa y reivindicación del magisterio ecuatoriano. El estudio se desarrolla mediante un análisis bibliográfico-documental y empírico, mediante la toma de datos de docentes que pertenecen al sector laboral público.

\section{Contexto sociopolítico del Correísmo}

En el contexto latinoamericano, desde la década del 70 del siglo XX, el neoliberalismo tuvo incidencia en los gobiernos latinoamericanos y ecuatorianos que tomaron decisiones guiados por orientaciones como, "la privatización de la educación que rebaja el docente al mercado y descalifica la profesión, quitando el reconocimiento y autonomía" (Terachi, 2012, pág. 53). Según Isch en Ecuador durante la última etapa democrática, previa al Correísmo, de 1980 al 2007, los proyectos neoliberales en la educación fueron una constante destrucción de lo nacional y local, por imposiciones de organismos financieros como el Fondo Monetario Internacional (FMI) y Banco Mundial. La deuda externa del país fue el condicionante de presión para la intervención de estas corporaciones que determinó cambios contrarios a una educación con visión nacional, hecho confirmado en informes de los propios bancos gestores de dichos proyectos (Isch, 2011, pág. 3-4). 
Sin duda la calidad educativa pública fue afectada por proyectos neoliberales, mientras que los gobiernos, estratégicamente, sistematizaron la política de culpar a la docencia por los deficientes resultados de aprendizaje evidenciados en los resultados de las evaluaciones como el Ser Bachiller (prueba de ingreso a las universidades). En estas condiciones la opción válida fue la protesta social en las calles, para hacer escuchar su descontento. Curiosamente en esta protesta nace Alianza País (AP) ${ }^{2}$, liderada por Rafael Correa, con alto apoyo popular, el movimiento político se comprometió por una transformación en la superestructura social, que se concretó en la Constitución 2008, pero que dejó intacta la riqueza en poder de la burguesía.

\subsection{El Buen Vivir para el Movimiento Alianza País (AP)}

El Sumak Kawsay o Buen Vivir ${ }^{3}$ al ser la filosofía indígena precolombina, fue acuñada por AP para fundamentar su plan de desarrollo nacional. Correa en su discurso lo utilizó hábilmente en su retórica política, como una antítesis para combatir a la vieja práctica política neoliberal que había sido el paradigma de gobiernos anteriores (Contrato Social por la Educación, 2012). Según Yánez en aquel momento la filosofía andina del Buen Vivir del gobierno correísta surge como fundamento que prioriza los derechos y el bienestar ciudadano con el que cada uno intenta forjar una vida digna (Yánez, 2014, pág. 8).

AP en su discurso de masas proclamaba el poder del pueblo, concebido como mandante, en su relación con los gobernantes. Yánez señala que la sociedad se convertía en actor trascendente en la toma de decisiones de Estado y sujeto de derechos (Yánez, 2014, pág. 9). Lamentablemente, al pasar de declaraciones y promesas políticas a acciones de gobierno, se expresan contradicciones. En conceptos del mismo Rafael Correa "el presidente de la República no es solo jefe del Poder Ejecutivo, es jefe de todo el Estado ecuatoriano" (Acosta, 2009, pág. 2), con lo cual "subyuga a las otras funciones del poder público y sobre todo al pueblo en la construcción de políticas, ya que los encargados como siempre fueron los organismos del gobierno" (Rojas, Aguilar, Piedra, 2018, pág. 53).

\subsection{La visión de derechos docentes}

Durante toda la historia según Sánchez el magisterio ha luchado contra la opresión del Estado, como un actor clave en la transformación de la sociedad, especialmente con su aportación al progreso social y a la calidad del sistema educativo, así analiza en la visión sociológica. Sin embargo, de ese importante rol que innegablemente ha jugado el docente, en el Ecuador, históricamente, los derechos docentes han sido relegados por parte de los gobiernos, especialmente en la década correísta (Sánchez, 2016, pág. 12).

Un proyecto emblemático del gobierno de AP es la "proclamación de la Constitución 2008, en la que se priorizan los derechos de la sociedad y naturaleza, por sobre el capital" (Zibell, 2017, pág. 21). Pese a que la inversión social en el primer periodo de gobierno mejora para la educación y se refleja mínimamente en el salario docente, no se alcanza cambios significativos. Estos cambios en la práctica resultaron ser las "mismas recetas neoliberales en la educación" (Isch, 2011, pág. 376). Es justamente el inicio de los conflictos entre el

\footnotetext{
2 Alianza País (AP): movimiento político que recoge el interés de todos los grupos sociales que conforman la sociedad ecuatoriana, propugna una vida digna en pro de edificar un mejor Ecuador (Chamorro, 2018, pág.19).

3 Sumak Kawsay: según Arteaga-Cruz (2017) es una propuesta que pretende centrar la sociedad en el sujeto, un intento de reconstrucción del vínculo sujeto-objeto, una creación de comunidad inspirada desde el ayllu y la propuesta del movimiento indígena ecuatoriano (pág. 909).
} 
gobierno y los docentes, pues la vulneración de los derechos laborales por el Estado ecuatoriano se incrementa.

\subsection{Situación de los derechos docentes}

Es un derecho humano universal la expresión de opinión que tienen las personas y la sociedad, no debería violentarse este derecho por acciones del Estado. Sin embargo, en el Ecuador, según el Plan nacional del Buen Vivir (2016) indica que:

Desde el advenimiento del Correísmo al poder (...) se han contabilizado por los menos 1409 casos de agresiones a la libertad de expresión en el Ecuador, que van desde "la aplicación selectiva y arbitraria de una legislación que ya de por si se cuenta como una de las más restrictivas del Continente, la censura previa vía la imposición de contenidos ejercida por distintas autoridades al frivolizar y abusar del derecho a la réplica y a la rectificación (aplicados indistintamente), decenas de casos de persecución a tuiteros, blogueros e incluso administradores de páginas de Facebook, censura de contenidos en Internet (...), el cierre de medios e incautación de equipos, nuevos insultos y discurso estigmatizante sobre blancos periodísticos concretos, agresiones físicas, prisión y represión en contra de quienes ejercen el derecho a la protesta (pág. 21).

Es evidente que se restringieron los derechos de opinión a los movimientos sociales que generaban pensamiento crítico, lucha social. Esa restricción recayó obviamente sobre la organización de la docencia, la UNE se vio muy afectada, ya que se le "prohibió el desarrollo de actividades sindicales en los establecimientos educativos estatales, calificándolos como actos políticos que desestabilizan al régimen democrático" (Isch, 2015, pág. 12), lo que afectó al accionar de la organización de los docentes, pero que contrariamente a la intención de desaparecerla, los maestros lo defendieron permanentemente, demostrando reconocimiento a su accionar histórico.

\subsection{Seguridad jurídica de la UNE}

La seguridad jurídica en términos planteados para el contexto ecuatoriano por Zabala- Egas (2011) asevera que es "cualquier acto, sea por acción u omisión, proveniente de autoridad la lesione o pretenda lesionarla causando daño en forma inminente" (pág. 14). Es decir, el Estado es la institución obligada a asegurar protección a la sociedad, pero al ser el causante de la violencia contra el magisterio, incumple normas constitucionales y legales. La UNE, durante una década fue víctima de inseguridad jurídica y agresión del Gobierno de AP.

Una decisión política que marcó el inicio de la conflictividad entre el gobierno y el gremio docente fue la implementación de la evaluación docente en el año 2009, en vez de capacitar, consensuar con el magisterio el mecanismo político fue el ataque verbal y acciones legales del presidente de la república. Esta acción que debió ser técnica se convirtió en: "una batalla muy dura, más política que técnica, con represión en las calles y policías en las aulas, destinada sobre todo a debilitar al sindicato y a los maestros. La "UNE fue derrotada en forma 'aplastante' sentenció Correa" (Torres, 2009, sección política). Las ofensas, permanentes, desmedidas y sistemáticas del aparato represor del gobierno contra la UNE, tuvieron el efecto planeado, afectaron a la seguridad jurídica de la UNE, así afirma Posso (2014):

(...) no más maltrato, no más descalificación (...) desde militares en las puertas hasta insultos del mandatario: mediocres, pelafustanes, corruptos, vagos (...) y al maestro lo estigmatizaron (...); así es como los 
docentes a pesar de que normativas nacionales e internacionales los amparan el gobierno violentó y fomentó el temor, perjudicando la educación, al estudiante y al docente (pág. 41).

La oferta demagógica correísta para alinear docentes adeptos a sus posiciones políticas fue la supuesta revalorización magisterial, sin embargo, este proceso precariza a los docentes, y genera reacción de lucha de la UNE, la que consecuentemente fue víctima de linchamiento de los medios públicos, degradación de sus dirigentes, incluso degradación de sectores sociales hacia la docencia. La lucha de la UNE se concentró en los derechos laborales de "contenido social para procurar las mejores condiciones de vida" (Aguilar, 1998, pág. 96), como: el salario, la jubilación, su estabilidad social, el escalafón, concursos de méritos, entre otros.

\subsection{Derechos salariales y de jornada laboral}

El salario es "un derecho que todo trabajador recibe, de acuerdo con su tiempo y capacidad de trabajo" (Comisión Nacional de los Derechos Económicos, Sociales y Culturales, 2012, pág. 11). Por tanto, "el salario docente es un derecho y a la vez, factor importante que incide en la calidad educativa, derivado de la experiencia, desempeño y evaluaciones, factores que garantizan la remuneración" (Ley Orgánica de Educación Intercultural, 2011, pág.21). Fue precisamente el salario uno de los elementos fundamentales que el gobierno de Correa utilizó para sofocar económicamente al docente, ya que, si bien hubo un ligero aumento, no tuvo equiparación con el incremento de la jornada semanal de trabajo, de 25 a 40 horas, lo que condujo inevitablemente a una acelerada pauperización de la profesión docente.

El salario del docente según el Congreso Nacional, previo a las reformas del gobierno Correa se componía de varios rubros salariales como: sueldo básico y adicionales. Los adicionales eran: el incremento por categoría, por función, por tipo de institución, por bono de ubicación rural, urbana, por frontera, compensación por antigüedad, por subsidio educativo-familiar y por incentivo de jubilación (Congreso Nacional Ecuador, 2000). Todos estos factores salariales se unificaron en un salario único, logrado con participación de la UNE.

Las reformas salariales en alguna medida beneficiaron a los docentes que en 2012 iniciaban su magisterio con un salario de 741 dólares, siendo un incremento considerable frente al anterior salario básico de 330 dólares más los bonos y subsidios. Claramente se trató de mejorar el salario docente, pero no fue un incremento equitativo; la reforma se consideró plena cuando se logró mantener las 10 categorías en el escalafón (Posso, 2014, pág. 103). Pero la ubicación docente en la nueva escala salarial ha demorado, ya casi, una década, tanto que hasta la actualidad no se beneficia a todo el magisterio que pertenece al estado.

Otra política implementada es la incidencia del desempeño docente en el salario, es decir que el resultado de la evaluación afectó a los docentes, según dispone la LOEI (2011) en el "Art. 136. Remuneración variable por eficiencia. - La remuneración variable estará vinculada al resultado que haya obtenido la o el docente en la carrera pública en la evaluación aplicada por el Instituto Nacional de Evaluación Educativa (...)” (pág. 36). El salario docente así regulado fue una política gubernamental que se implementó para lograr eficiencia de los servidores públicos, entre otros los docentes.

Según Isch la evaluación docente ejecutada por el Ministerio de Educación del Ecuador, como mecanismo de mejoramiento profesional, y sobre todo para cumplir estándares de calidad educativa fue finalmente una prueba de premio y castigo para el magisterio (Isch, 2010, pág. 20). A la vez que se incrementó las horas de clases semanales a 30 y 10 horas 
para actividades administrativas, en desmedro de la función pedagógica, lo cual, limita que el profesor piense, lea y escriba sobre su experiencia académica.

La evaluación docente ejecutada por el Ministerio de Educación del Ecuador "como mecanismo de mejoramiento profesional, y sobre todo para cumplir estándares de calidad educativa, fue finalmente una prueba de premio y castigo para el magisterio" (Isch, 2010, pág. 20). A la vez que se incrementó las horas de clases semanales, en total 40 horas, 30 para clases y 10 para actividades administrativas. El incremento fue en desmedro de la función pedagógica, pues, limita que el profesor piense, lea y escriba sobre su experiencia académica. Concomitantemente a las disposiciones explicadas, según afirma Chamorro (2018):

Los docentes tienen una sobrecarga de trabajo, pasan más tiempo llenando matrices, recogiendo evidencias, tomando fotos para presentarlas a las autoridades institucionales y a los Distritos. (...), la creciente importancia que le otorga el MinEduc a enfoques tecnocráticos e instrumentales de la educación y la pedagogía (pág. 83).

Desde la administración correísta del gobierno hoy se confirma la sobrecarga burocrática forzada al docente. Se reconoce el desmedro de la calidad de educación, ya que los indicadores no son alentadores pese a los aparentes cambios tan pregonados por el gobierno anterior, y aceptados al inicio del gobierno de Lenin Moreno, pero que el mismo "Fander Falconí, titular del MinEduc, informó que se detectó una excesiva sobrecarga a los catedráticos" (El Telegrafo, 2006, pág. 2), lo cual es una importante autocrítica al poder.

\subsection{Estabilidad laboral y jubilación docente}

Desde el gobierno de AP, sobre todo para posicionar a la Red de Maestros, en desmedro de la UNE, Correa en el 2016 afirmaba reiteradamente que en el Ecuador había un muy alto número de maestros, casi 60 mil, que laboraban en planteles públicos sin contratos y que tampoco estaban registrados en el Ministerio de Educación. Además, percibían salarios inferiores a lo legalmente establecido antes del Correísmo, contrariamente a lo que se pregonaba desde las esferas oficiales, Isch (2010) asevera que:

(...) no cumplía ni siquiera con la generación de las 12 mil partidas acordadas a inicio del gobierno hasta noviembre de 2008 se habían entregado apenas una cantidad cercana a los 3.000 nombramientos mientras más de 6 mil docentes estarían trabajando por contratos temporales, manteniendo la flexibilización laboral propia del neoliberalismo (pág. 18).

Pese a la permanente propaganda gubernamental, sobre todo en las sabatinas, cinco años después, ya en el 2014, las cifras no variaban mucho como lo sostiene el mismo Isch (2015):

De los 147 mil 129 docentes del sistema nacional de educación hasta el año 2013, solo 99.611 tienen nombramiento que garantiza su estabilidad, mientras 47 mil 518 laboran bajo la modalidad de "contrato temporal", con un sueldo entre 430 y 530 dólares (por lo general, alrededor del $50 \%$ del salario de quien tienen nombramiento con estabilidad laboral) (pág. 12).

Concomitantemente se mantuvo modelos de gestión política como la precarización laboral, bajos sueldos, afectación a derechos básicos, este fue un punto clave en donde el gobierno, logró manipular a los docentes para que apoyen la estrategia política de un nuevo gremio 
llamada la Red de Maestros en La Década Perdida en Educación. Al respecto, Vargas-Meza (2016) sustenta que:

Los docentes contratados, no reciben su nombramiento definitivo. Esto es motivo de chantaje, porque deben acudir a las reuniones que convocan y "portarse bien'. Últimamente los Distritos contratan docentes para el año lectivo, los despiden diciéndoles que ese puesto ocupará quienes ganaron el concurso Ser Maestro (pág. 48).

La narrativa del movimiento AP sembró falsas esperanzas sobre salarios docentes, pues aplicó las mismas recetas de administraciones neoliberales, incluso con mayor carga ideológica, se vulneró la garantía de derechos, se infringió permanente la LOEI ${ }^{4}$ y sobretodo la Constitución “(...) prohibió la existencia de cualquier contrato precario" (Isch, 2010, pág. 19). Desde el advenimiento en el poder en 2007, AP "ofreció mejorar la jubilación del docente y de los trabajadores ecuatorianos en general, quienes se jubilaban a muy avanzada edad y con salarios indignantes" (Correa, 2016, pág. 7), a pesar de la propuesta de revalorizar al docente; el gobierno de AP en el 2011 mediante las reformas a la LOEI, ejecuta su oferta, ya que deroga el "Decreto Supremo 719, publicado en el RO del 5 de mayo de 1964, que estableció un aporte adicional del 5\% de los aportes patronales y personales del magisterio, para financiar la jubilación de los profesores" (Posso, 2014, pág. 98).

En 2015 el gobierno de Correa propina otro golpe político al magisterio ecuatoriano, esta vez, mediante el retiro de los recursos con que el Estado financiaba las pensiones jubilares. El gobierno retira el $40 \%$ de apoyo oficial, quebrantando la garantía y obligación del Estado con los jubilados dispuesto por la Ley Orgánica para la Justicia Laboral y Reconocimiento del Trabajo en el Hogar, aprobada por la Asamblea Nacional en 2015, con votos de los diputados de AP (El Universo, 2015).

En mayo de 2015, el gobierno de Correa, con el argumento de que el Estado ayudó a los fondos de cesantía privados de los trabajadores de instituciones públicas en la dolarización del año 1999, pasó el Fondo de Cesantía del Magisterio Ecuatoriano (FCME) a la administración del Estado, supuestamente en aplicación del artículo 220 de la Ley de Seguridad Social. El monto que se tomó el Correísmo fue de aproximadamente "402 millones de dólares" (Unión Nacional de Educadores, 2015, pág. 5).

Uno de los incumplimientos del Correísmo de mayor afectación al magisterio fue no haber cancelado deudas jubilares a docentes ecuatorianos. Es emblemático el caso de "Cumandá Páez, docente que murió de cáncer en el estómago sin recibir los estímulos a la jubilación voluntaria. Aún con vida, la maestra grabó videos criticando los trámites legales que le exigieron seguir para demostrar que ya no podía trabajar" (Contrato Social por la Educación, pág. 4). El gobierno correísta deslindó su responsabilidad aduciendo que las causas fueron los problemas económicos internacionales como el "desplome del precio del petróleo, apreciación del dólar, desaceleración de China, que es el principal financista del planeta" (Correa, 2016, pág. 8).

\subsection{Derechos sindicales}

La nueva Constitución 2008 dispone la participación ciudadana y el Buen Vivir como mandatos novedosos que fomentan la inclusión de la sociedad. En la práctica estos principios se quebrantan, puesto que "prohíbe la paralización de servicios públicos, entre

${ }^{4}$ Ley Orgánica de Educación Intercultural. 
ellos la educación" (Posso, 2014, pág. 110), lo que vulnera derechos de trabajadores a la resistencia y lucha social.

En el año 2016 como muestra objetiva de la criminalización de la lucha social, "el gobierno del presidente Rafael Correa disolvió (...) el principal gremio de profesores dependientes del Estado, Unión Nacional de Educadores, aduciendo que no cumple sus propios estatutos y reglamentos acerca de organizaciones sociales." (El Universo, 2016, pág. 1), así se atacó a la representatividad del gremio, mermando la capacidad de defensa de los derechos de los docentes. Esta disposición generó protestas de la UNE y los docentes. El Correísmo lanzó una sostenida propaganda para: "asociar al gremio de los docentes: vagancia, inoperancia, politización e ineficiencia. Postura que se apalancó, por lo demás, en una suerte de desgaste y deslegitimación del sindicato" (Posso, 2014, pág. 119).

Para el 2011 se reafirmaría el conflicto entre el gobierno y el gremio de maestros, ya que mediante la LOEI se coarta "las posibilidades de la huelga y la movilización social del gremio, como mecanismo de lucha por derechos "(...), fundamentalmente, limitan, la capacidad del sindicato de agregar las demandas de sus agremiados" (Posso, 2014, pág. 101). Con esta disposición se mermó el derecho del sindicato a reclamar el poder del gremio. Las normativas que sistemáticamente se iban forjando tuvieron el propósito de desaparecer a la UNE, retirándola su personería jurídica como finalmente sucedió.

\subsection{Inhabilitación de la UNE, surgimiento de la RED de maestros}

Desde el año 2010 en el discurso gubernamental el "propio Rafael Correa llamó a conformar una nueva UNE" (Isch, 2010, pág. 18), todas las acciones gubernamentales denotan la iniciativa del gobierno por perseguir e inhabilitar a la UNE, esto tuvo efecto hasta el 2015, en que surge la Red de Maestros como nuevo sindicato creado por AP. Al respecto, Pinos (2017) afirmaba que: "el gobierno impulsó la creación de un nuevo sindicato llamado Red de Maestros y Maestras por la Revolución Educativa, su número de afiliados crece, aunque su composición, estructura e influencia no alcanza la magnitud de la UNE" (pág. 6).

En el discurso del primer aniversario de la Red de Maestros, su ideólogo Rafael Correa afirmaba que los maestros inscritos en dicho programa estaban "para cuidar, no un Gobierno, no un partido político, sino para cuidar lo más preciado que tiene la nación: nuestros niños, nuestros adolescentes, nuestros jóvenes, y su educación" (Correa, 2016, pág. 4). Este gremio fue intermediario para el ingreso de cualquier profesional, incluso bachilleres al magisterio público, factor que en los siguientes años trajo graves efectos en deterioro de la calidad educativa, incluso actos de acoso y violaciones a menores, como consta en la revista Vistazo, según la cual "una comisión especial de la Asamblea Nacional determinó la responsabilidad política de los exministros de educación Augusto Espinosa y Freddy Peñafiel en los casos de abuso sexual en colegios" (Santos, 2018, pág. 4).

\section{Metodología}

1. El enfoque del estudio es cualitativo, en razón que se abordó las variables en estudio, mediante un análisis a profundidad; el diseño es no experimental porque no se manipula variables, también es de características: retrospectiva y transversal, ya que se trató sobre hechos sucedidos; es descriptiva porque se caracterizan los derechos docentes durante el gobierno correísta del 2007 hasta el 2017. El fenómeno se analiza en su realidad socio-natural. Finalmente, es de tipo bibliográfico-documental y de campo porque se sustenta en escritos publicados y percepciones de docentes públicos. 
2. Se aplicó una encuesta a miembros activos del magisterio público. La población fue de 300 docentes públicos de distintos planteles educativos de la provincia de Pichincha. Contestaron el cuestionario 33 docentes, un 11\% del total, mediante el programa Google Drive, abierto por 30 días. El muestreo fue intencional, método que como afirma Alaminos (2006), "constituye una estrategia no probabilística válida para la recolección de datos, en especial para muestras pequeñas y muy específicas" (pág. 50). La muestra tiene limitada representatividad. Varios maestros manifestaron su decisión de no responder por temor a represalias del gobierno. Complementariamente se aplicó entrevistas a expertos: docentes de educación básica y bachillerato, jubilados, ex/dirigentes de la UNE, un asesor de la disuelta Asamblea Nacional Constituyente y a un docente de la Universidad Andina Simón Bolívar.

3. Se organizó la base de datos y se procesó la estadística descriptiva en el programa SPSS, posteriormente se trabajó el análisis dinámico para obtener resultados, analizar discutir y lograr conclusiones. En el cuadro 1 consta el resumen del muestreo.

\begin{tabular}{crrr}
\hline & Frecuencia & Porcentaje & $\begin{array}{r}\text { Porcentaje } \\
\text { acumulado }\end{array}$ \\
\hline Femenino & 17 & 51,5 & 51,5 \\
Masculino & 16 & 48,5 & 100,0 \\
Total & 33 & 100,0 & \\
\hline
\end{tabular}

Cuadro 1. Docentes encuestados por género

\section{Resultados y discusión}

Una variable esencial para analizar la situación de los derechos docentes es la libertad de opinión que los docentes consideraron transgredida. El cuadro 2 sintetiza el resultado del ítem sobre transgresión de derechos de opinión, cuyas respuestas más significativas son que: el $36.4 \%$ de docentes encuestados, manifiestan estar totalmente de acuerdo, y en la misma dirección, un 33\% están de acuerdo. Integralmente, un 69,7\% de docentes perciben que sus derechos han sufrido transgresión. Apenas un $20 \%$ de docentes expresan no haber sufrido atropello de sus derechos de opinión.

\section{Frecuencia Porcentaje Porcentaje acumulado}

\begin{tabular}{lrrr}
\hline Totalmente en desacuerdo & 2 & 6,1 & 6,1 \\
En desacuerdo & 5 & 15,2 & 21,2 \\
Ni de acuerdo ni en desacuerdo & 3 & 9,1 & 30,3 \\
De acuerdo & 11 & 33,3 & 63,6 \\
Totalmente de acuerdo & 12 & 36,4 & 100,0 \\
Total & 33 & 100,0 & \\
\hline
\end{tabular}

Cuadro 2. Libertad de opinión

Un derecho humano fundamental es la libertad de reunión y asociación pacífica con fines gremiales, reconocido en la declaración Derechos Humanos de la ONU y en la Constitución 
2008. Los resultados en el cuadro 3 ilustran que un 56,6\%, más de la mitad de los docentes encuestados, respondieron las opciones: totalmente de acuerdo y de acuerdo, en que hubo afectación a la libertad de reunión para los maestros ecuatorianos en el régimen correísta. El 21\% de docentes tienen una posición distinta, afirman que no hubo afectaciones a la libertad de reunión.

\begin{tabular}{lrrr}
\hline & Frecuencia & Porcentaje & Porcentaje acumulado \\
\hline Totalmente en desacuerdo & 2 & 6,1 & 6,1 \\
En desacuerdo & 5 & 15,2 & 21,2 \\
Ni de acuerdo ni en desacuerdo & 7 & 21,2 & 42,4 \\
De acuerdo & 7 & 21,2 & 63,6 \\
Totalmente de acuerdo & 12 & 36,4 & 100,0 \\
Total & 33 & 100,0 & \\
\hline
\end{tabular}

Cuadro 3. Libertad de reunión y asociación docente

El cuadro 4 resume las percepciones docentes sobre la afectación a sus derechos sindicales por parte del gobierno correísta, que socavó la participación de su gremio magisterial histórico, la UNE. El 72,7\% de los encuestados están totalmente de acuerdo y en desacuerdo sobre la reducción de los derechos sindicales docentes. Una posición contraria manifiesta en un $18 \%$ están totalmente en desacuerdo, pues estiman no haber sido afectados sus derechos gremiales.

\begin{tabular}{lrrr}
\hline & Frecuencia & Porcentaje & $\begin{array}{c}\text { Porcentaje } \\
\text { acumulado }\end{array}$ \\
\hline Totalmente en desacuerdo & 2 & 6,1 & 6,1 \\
En desacuerdo & 4 & 12,1 & 18,2 \\
Ni de acuerdo ni en desacuerdo & 3 & 9,1 & 27,3 \\
De acuerdo & 11 & 33,3 & 60,6 \\
Totalmente de acuerdo & 13 & 39,4 & 100,0 \\
Total & 33 & 100,0 & \\
\hline \multicolumn{4}{c}{ Cuadro 4. Afectación a derechos docentes }
\end{tabular}

Cuadro 4. Afectación a derechos docentes

El cuadro 5 resume el análisis sobre el conflicto existente entre el gremio docente y el gobierno. El gobierno responsabilizó a la UNE como el mayor causante de la crisis educativa del país. El dato empírico demuestra que un 72,5 \% de docentes investigados se alinean con las opciones: totalmente en desacuerdo y en desacuerdo, así manifiestan su oposición a que son los maestros causantes de la crisis educativa ecuatoriana; mientras que solamente el $15 \%$ de los docentes se mostraron indiferentes a la pregunta. Finalmente, un $12 \%$ de encuestados se alinean con las afirmaciones del discurso sobre el aspecto en estudio.

\begin{tabular}{lrrr}
\hline & Frecuencia & Porcentaje & $\begin{array}{r}\text { Porcentaje } \\
\text { acumulado }\end{array}$ \\
\hline Totalmente en desacuerdo & 16 & 48,5 & 48,5 \\
En desacuerdo & 8 & 24,2 & 72,7 \\
Ni de acuerdo ni en desacuerdo & 5 & 15,2 & 87,9 \\
De acuerdo & 2 & 6,1 & 93,9 \\
Totalmente de acuerdo & 2 & 6,1 & 100,0 \\
Total & 33 & 100,0 & \\
\hline
\end{tabular}

Cuadro 5. Crisis educativa, UNE, políticas 
El cuadro 6 contiene el análisis de la variable sobre si se mejoró los derechos laborales de los docentes en el gobierno correísta. Al respecto el 66,7\% de encuestados manifiestan estar totalmente en desacuerdo y en desacuerdo. El 24\% tienen una posición contraria a la mayoría de las respuestas, pues consideran que las condiciones de sus derechos laborales sí mejoraron en el gobierno de Rafael Correa.

\begin{tabular}{lrrr}
\hline & Frecuencia & Porcentaje & \multicolumn{2}{c}{$\begin{array}{c}\text { Porcentaje } \\
\text { acumulado }\end{array}$} \\
\hline Totalmente en desacuerdo & 13 & 39,4 & 39,4 \\
En desacuerdo & 9 & 27,3 & 66,7 \\
Ni de acuerdo ni en desacuerdo & 3 & 9,1 & 75,8 \\
De acuerdo & 5 & 15,2 & 90,9 \\
Totalmente de acuerdo & 3 & 9,1 & 100,0 \\
Total & 33 & 100,0 & \\
\hline
\end{tabular}

Cuadro 6. Derechos laborales de docentes

El cuadro 7 compendia las apreciaciones de los docentes sobre la participación la UNE en comisiones de Ministerio de Educación para gestionar procesos de ingreso, movilidad y promoción docente. Un amplio $72,7 \%$ se inclinan por las opciones totalmente de acuerdo y de acuerdo. Apenas un 18,2\% opinan que el magisterio mantuvo derechos de participación.

\begin{tabular}{lrrr}
\hline & Frecuencia & Porcentaje & $\begin{array}{c}\text { Porcentaje } \\
\text { acumulado }\end{array}$ \\
\hline Totalmente en desacuerdo & 2 & 6,1 & 6,1 \\
En desacuerdo & 4 & 12,1 & 18,2 \\
& & & 27,3 \\
Ni de acuerdo ni en desacuerdo & 3 & 9,1 & 60,6 \\
De acuerdo & 11 & 33,3 & 100,0 \\
Totalmente de acuerdo & 13 & 39,4 & \\
Total & 33 & 100,0 & \\
\hline
\end{tabular}

Cuadro 7. Participación UNE

A cerca de la correcta aplicación de la LOEI y reglamentos de escalafón docente que norman el desarrollo profesional para movilidad y promoción, los resultados en el cuadro 8 muestran que el $63,6 \%$ de docentes responden estar totalmente en desacuerdo y en desacuerdo, el Correísmo no respetó y no aplicó las leyes vigentes. Pero también es considerable que el $27,3 \%$ de docentes perciben que hubo una adecuada aplicación de normativas de desarrollo docente.

\begin{tabular}{lrrr}
\hline & Frecuencia & Porcentaje & $\begin{array}{r}\text { Porcentaje } \\
\text { Acumulado }\end{array}$ \\
\hline Totalmente en desacuerdo & 11 & 33,3 & 33,3 \\
En desacuerdo & 10 & 30,3 & 63,6 \\
Ni de acuerdo ni en desacuerdo & 3 & 9,1 & 72,7 \\
De acuerdo & 6 & 18,2 & 90,9 \\
Totalmente de acuerdo & 3 & 9,1 & 100,0 \\
Total & 33 & 100,0 & \\
\hline
\end{tabular}

Cuadro 8. Aplicación de la LOEI

Uno de los elementos más determinantes para el bienestar humano es el salario por el trabajo realizado. En este ítem, al consultar sobre una remuneración docente justa 
implementada por el Correísmo, de acuerdo a los resultados del cuadro 9 el 66,7\% sostiene estar en desacuerdo y totalmente en desacuerdo en su apreciación, es decir, la mayoría de encuestados consideran que su estipendio fijado por el gobierno no tuvo correspondencia con la jornada incrementada de 25 a 40 horas semanales. Previo a la nueva jornada semanal, muchos docentes complementaban su salario con contratos adicionales, lo que eliminó, en desmedro del bienestar familiar.

\begin{tabular}{|c|c|c|c|}
\hline & Frecuencia & $\begin{array}{l}\text { Porcentaje } \\
\text { válido } \\
\end{array}$ & $\begin{array}{l}\text { Porcentaje } \\
\text { acumulado }\end{array}$ \\
\hline Totalmente en desacuerdo & 13 & 39,4 & 39,4 \\
\hline En desacuerdo & 9 & 27,3 & 66,7 \\
\hline $\begin{array}{l}\mathrm{Ni} \text { de acuerdo ni en } \\
\text { desacuerdo }\end{array}$ & 3 & 9,1 & 75,8 \\
\hline De acuerdo & 5 & 15,2 & 90,9 \\
\hline Totalmente de acuerdo & 3 & 9,1 & 100,0 \\
\hline Total & 33 & 100,0 & \\
\hline
\end{tabular}

El cuadro 10 sintetiza acerca de la flexibilidad laboral aplicada en la contratación docente por el Correísmo. El principal resultado es que más del 66,7\% de docentes manifiestan estar totalmente en desacuerdo y en desacuerdo con que el gobierno haya implementado la contratación docente permanente. Efectivamente, las contrataciones temporales se incrementaron para docentes sin formación. Un porcentaje del $24,3 \%$ de docentes encuestados se apega a las opciones totalmente de acuerdo y de acuerdo, indican que hubo estabilidad laboral y que no se ha afectado a derechos de estabilidad laboral.

\begin{tabular}{lrrr}
\hline & Frecuencia Porcentaje & $\begin{array}{l}\text { Porcentaje } \\
\text { acumulado }\end{array}$ \\
\hline Totalmente en desacuerdo & 4 & 12,1 & 12,1 \\
En desacuerdo & 6 & 18,2 & 30,3 \\
Ni de acuerdo ni en desacuerdo & 6 & 18,2 & 48,5 \\
De acuerdo & 9 & 27,3 & 75,8 \\
Totalmente de acuerdo & 8 & 24,2 & 100,0 \\
Total & 33 & 100,0 & \\
\hline
\end{tabular}

Cuadro 10. Flexibilización laboral

El cuadro 11 extracta el resultado de la interrogante sobre la jubilación docente y su afectación por las políticas implementadas en el gobierno correísta. El porcentaje de respuesta es que casi el $70 \%$ de docentes se inclinaron por las opciones: totalmente de acuerdo y de acuerdo; lo que refleja que la jubilación del docente si se vio afectada por las políticas implementadas desde el poder. Solamente un escaso $18 \%$ de docentes considera que no hay transgresión a la jubilación docente. Es decir, más de la mitad de los encuestados evidenciaron una afectación del derecho de una jubilación digna de los docentes fiscales.

Frecuencia Porcentaje Porcentaje acumulado

\begin{tabular}{llll}
\hline Totalmente en desacuerdo & 3 & 9,1 & 9,1 \\
\hline
\end{tabular}




\begin{tabular}{lrrr}
\hline En desacuerdo & 3 & 9,1 & 18,2 \\
Ni de acuerdo ni en desacuerdo & 4 & 12,1 & 30,3 \\
De acuerdo & 9 & 27,3 & 57,6 \\
Totalmente de acuerdo & 14 & 42,4 & 100,0 \\
Total & 33 & 100,0 & \\
\hline
\end{tabular}

Cuadro 11. Jubilación docente

Según los resultados obtenidos en la encuesta respecto a la situación de derechos docentes, como consta en el cuadro 12, se observa una relativa concordancia entre los docentes encuestados. El 72,7\% de encuestados, es decir, tres de cuatro docentes están totalmente en desacuerdo y en desacuerdo, que se haya respetado los derechos de los docentes ecuatorianos promulgados en la Constitución 2008, LOEI, LOSEP y la séptima política del Plan Decenal.

\begin{tabular}{lrrr}
\hline & Frecuencia & Porcentaje & $\begin{array}{c}\text { Porcentaje } \\
\text { acumulado }\end{array}$ \\
\hline Totalmente en desacuerdo & 14 & 42,4 & 42,4 \\
En desacuerdo & 10 & 30,3 & 72,7 \\
Ni de acuerdo ni en desacuerdo & 3 & 9,1 & 81,8 \\
De acuerdo & 4 & 12,1 & 93,9 \\
Totalmente de acuerdo & 2 & 6,1 & 100,0 \\
Total & 33 & 100,0 & \\
\hline
\end{tabular}

Cuadro 12. Respeto derechos docentes

Según consta en el cuadro 13 se investigó sobre la crisis educativa en el Ecuador. El 73\% de docentes encuestados se alinean con las opciones totalmente en desacuerdo y en desacuerdo. Las políticas públicas de la educación son emanadas del gobierno y aprobadas por la Asamblea Nacional, el docente tiene la responsabilidad de aplicar procesos curriculares, en la escuela exclusivamente, no la administración del Estado. Desde el gremio docente permanentemente se han hecho propuestas educativas al Ministerio de Educación que no lo acogió, y más bien aplico políticas neoliberales.

\begin{tabular}{lrrr}
\hline & Frecuencia & Porcentaje & \multicolumn{2}{c}{$\begin{array}{c}\text { Porcentaje } \\
\text { acumulado }\end{array}$} \\
\hline Totalmente en desacuerdo & 16 & 48,5 & 48,5 \\
En desacuerdo & 8 & 24,2 & 72,7 \\
Ni de acuerdo ni en desacuerdo & 5 & 15,2 & 87,9 \\
De acuerdo & 2 & 6,1 & 93,9 \\
Totalmente de acuerdo & 2 & 6,1 & 100,0 \\
Total & 33 & 100,0 & \\
\hline
\end{tabular}

Cuadro 13. Percepción docente sobre crisis educativa

El cuadro 14 condensa las percepciones docentes respecto a que en el gobierno correísta el magisterio ecuatoriano sufrió sumarios, sanciones e incluso despedidos de su trabajo. Se observa que la mayoría de los encuestados, cerca del 64\% responden estar totalmente de acuerdo y de acuerdo en sentir temor a la represión. Por lo mismo, se puede deducir que los docentes tuvieron temor a sufrir sanciones laborales, este factor determinó que la gran mayoría desmovilice, se centre a cumplir con disposiciones de sus autoridades educativas e incluso se aísle del resto de docentes para no ser perseguido por supuestos o por hechos de 
defensa de derechos. El gobierno correísta, sin duda, implantó una política de control extremadamente represiva y sancionatoria para todos los docentes como política de Estado.

\begin{tabular}{lrrr}
\hline & Frecuencia & Porcentaje & $\begin{array}{r}\text { Porcentaje } \\
\text { acumulado }\end{array}$ \\
\hline Totalmente en desacuerdo & 3 & 9,1 & 9,1 \\
En desacuerdo & 3 & 9,1 & 18,2 \\
Ni de acuerdo ni en desacuerdo & 6 & 18,2 & 36,4 \\
De acuerdo & 7 & 21,2 & 57,6 \\
Totalmente de acuerdo & 14 & 42,4 & 100,0 \\
Total & 33 & 100,0 & \\
\hline
\end{tabular}

Cuadro 14. Percepción docente de temor por sanciones

La información cualitativa confirmatoria de los datos proporcionados por la encuesta se obtuvo mediante entrevistas aplicadas a académicos ecuatorianos vinculados al fenómeno en estudio, esto es; el deterioro de los derechos docentes fiscales, durante el periodo gubernamental 2007-2017. El análisis e interpretación de la entrevista se plasmó mediante procedimientos cualitativos para "analizar textos 'crudos', como el método de palabras claves en contexto (KWIC por sus siglas en inglés)," (Fernández-Núñez, 2006, pág. 3). El KeyWord In Context es pertinente para trabajar sinonimia y antonimia, a partir de datos cualitativos y subjetivos. Los datos de entrevista se codificaron en un cuadro con las respuestas de expertos, luego se realizó análisis individual por pregunta, así como también un análisis integral de los datos e interpretación; los aspectos más relevantes encontrados son:

- Los expertos entrevistados, mayoritariamente, expresan que hubo deterioro en los derechos de opinión de los docentes, así como en sus libertades de reunión gremial, incluso amenazas, persecución y sanciones a docentes.

- En la situación gremial de la UNE en la etapa correísta, mayoritariamente, los entrevistados destacan su lucha por los derechos docentes públicos, valoran una organización social antagónica con el gobierno. Afirman que la UNE fue objeto de abuso de poder político, llegó hasta su ilegalización e incautación de sus bienes. En cuanto a la Red de Maestros adscrita al gobierno, la mayoría de los entrevistados cataloga como una organización momentánea del gobierno correísta.

- Los entrevistados destacan también como un aspecto relevante las sanciones a docentes de oposición agremiados en la UNE por el gobierno, mientras que unos indican salir a protestar por problemas económicos, otros profesores señalan que salían a protestas por oponerse al sistema educativo que no ha cambiado por ser miembros de la UNE. Los docentes caracterizan al gobierno correísta como totalitario-fascista contra toda forma de lucha social, centrada sobre todo en los docentes y servidores del Estado.

- Un factor muy explicado por los expertos fue la eliminación de componentes salariales en la remuneración del docente. La rebaja salarial es una forma de ahorro estatal, y a la vez, también una forma de sobreexplotación laboral.

\section{Conclusiones}

Acerca del objetivo trazado en el artículo sobre investigar la situación de derechos docentes públicos y la situación gremial UNE durante el Correísmo, se determina que durante este gobierno se promulgó, al inicio, un discurso de izquierda que fue contradecido con su práctica represiva, pues, se afectó al derecho docente, a la calidad de vida en su desempeño profesional y gremial, es decir, la pregonada revalorización de la profesión docente fue 
solamente un eslogan político. Los derechos laborales docentes en el gobierno correísta, efectivamente, tuvo manifestaciones de irrespeto a acuerdos internacionales de derechos humanos, así como normativas legales internas; incluso pudo haber incurrido en violación de derechos humanos de los docentes ecuatorianos.

Los docentes en la década correísta fueron gravemente afectados en organización gremial, de resistencia, de libertad de opinión, de derechos salariales y de derecho al trabajo. Otros derechos docentes afectados fueron los de desarrollo profesional, movilidad y jubilación.

Indudablemente la década de gobierno correísta implantó una política de control extremadamente represiva y sancionatoria para el magisterio fiscal, como política de Estado. Según afirman Sánchez 2016, UNESCO 2015 y McKinsey \& Company 2008, una adecuada atención al sector docente impacta muy fuertemente en la calidad educativa de un país. Al brindar bienestar a cada docente, en lo profesional, personal y social para que pueda gozar de un nivel adecuado de vida, éste genera un alto desempeño que aporta al desarrollo de la sociedad. Justamente, la práctica correísta contradice con lo manifestado, porque las acciones deterioraron la vida del docente ecuatoriano, lo desmotivaron, en desmedro de la educación ecuatoriana.

El acoso e ilegalización a la UNE, así como la creación y apoyo a la Red de Maestros, repercutieron en la docencia, ya que los maestros sintieron desprotección, inmovilización profesional, reubicación e incluso despido. Queda aún, por esclarecer, varios casos gestados por el Correísmo en contra de docentes ecuatorianos que seguramente en el futuro se hará justicia. 


\section{Bibliografía}

Acosta, A. (13 de Marzo de 2009). Política. Se le chispoteó algo al Presidente, pág. 2.

Aguilar, M. (Abril de 1998). Las tres generaciones de los derechos humanos. Derechos Humanos Òrgano Informativo de la Comisión de Derechos Humanos del Estado de México(30), 93-103.

Alaminos, A. (2006). El muestreo en la investigación social. En A. Alaminos, \& L. Castejón, Elaboración, análisis e interpretación de encuestas, cuestionarios y escalas de opinión (págs. 41-55). Alicante-España: Editorial Marfil, S.A.

Arteaga-Cruz, E. L. (2017). Buen Vivir (Sumak Kawsay): definiciones,crítica e implicaciones en la planificación del desarrollo en Ecuador. Rio de Janeiro: SAÚDE DEBATE . Recuperado el 11 de julio de 2019 de https://www.scielosp.org/article/ssm/content/raw/?resource_ssm_path=/media /assets/sdeb/v41n114/0103-1104-sdeb-41-114-0907.pdf

Chamorro, A. B. (2018). Análisis de los derechos de docentes en el período presidencial, bajo la égida del Movimiento Alianza País. Quito: Universidad Central del Ecuador. Retrieved from. Recuperado el 12 de julio de 2019 de http://www.dspace.uce.edu.ec/bitstream/25000/16877/1/T-UCE-0010-FIL141.pdf

Comisión Nacional de los Derechos Económicos, Sociales y Culturales. (2012). Pacto Internacional de Derechos Económicos, Sociales y Culturales. México: Lexis. $\begin{array}{lllllll}\text { Recuperado el } & 8 & \text { de } & \text { julio } & \text { de } & 2019 & \text { de }\end{array}$ http://www.cndh.org.mx/sites/all/doc/cartillas/7_Cartilla_PIDESCyPF.pdf

Congreso Nacional Ecuador. (2000). Suplement 20 de julio. Recuperado el 23 de agosto de 2019 de https://docplayer.es/11104024-Ley-de-carrera-docente-y-escalafon-delmagisterio-nacional-ley-no-94.html

Contrato Social por la Educación. (2012). Educación y buen vivir: reflexiones sobre su construcción (Primera ed.). Quito: Contrato Social por la Educación. Recuperado el 7 de julio de 2019 de https://biblio.flacsoandes.edu.ec/catalog/resGet.php?resId=55490

Contrato Social por la Educación. (s.f.). Contrato Social por la Educación. Recuperado el 14 de Marzo de 2019, de http://contratosocialecuador.org/index.php/noticias/noticias-y-eventos-cse/572maestras-os-luchan-por-su-derecho-a-jubilarse

Correa, R. (2016). Retrieved from www.presidencia.gob.ec. Recuperado el 12 de abri de 2019 https://www.presidencia.gob.ec/wpcontent/uploads/downloads/2016/02/Plan-Decenal-de-Educacion.pdf

El Universo. (2015). Suplemento 14 de abril. Recuperado el 12 de julio de 2019 de www.eluniverso.com:

https://www.eluniverso.com/noticias/2015/04/14/nota/4770421/aprobadaley-justicia-laboral-que-reforma-seguridad-social

El Universo. (2016). Suplemento 18 de agosto. Recuperado el 25 de junio de 2019 www.eluniverso.com. 
https://www.eluniverso.com/noticias/2016/08/18/nota/5749674/ministerioeducacion-disuelve-union-nacional-educadores

El Telégrafo. (2019). Suplemento 25 de enero. Recuperado el 14 de noviembre de 2019 www.eltelegrafo.com.ec. https://www.eltelegrafo.com.ec/noticias/judicial/12/informe-persecuciongobierno-correa

Fernández-Núñez, L. (2006). ¿Cómo analizar datos cualitativos? Institut de Ciències de l'Educació. Universitat de Barcelona., 7, 1/13.

Isch, E. (2010). Por una evaluación para la educación, NO para la exclusión. Intercambio(1), 16-22. Recuperado el 12 de agosto de 2019 de http://es.idea-network.ca/wpcontent/uploads/2012 /04/intercambio-es-ano3-no1-julio-2010.pdf

Isch, E. (2011). Las actuales propuestas y desafíos en educación: el caso ecuatoriano. Educação \& Sociedade, 373-391. Recuperado el 18 de julio de 2019 de http://www.scielo.br/pdf/es/v32n115/v32n115a08.pdf

Isch, E. (2015). Las reformas educativas modernizadoras y el ataque a la organización de los maestros en el Ecuador. Intercambio(7), 11-13.

McKinsey \& Company (2008). Cómo hicieron los sistemas educativos con mejor desempeño del mundo para alcanzar sus objetivos. Programa de Promoción de la Reforma Educativa en América Latina y el Caribe(41). Recuperado el 17 de julio de 2019 https://www.oei.es/historico/noticias/spip.php?article3077

Pinos, J. (2017, Agosto). La sindicalización docente. Entre el derecho a la huelga y la prohibición de limitar un servicio público. Revista Contribuciones a las Ciencias Sociales. Retrieved from. Recuperado el 8 de junio de 2019 http://www.eumed.net/rev/cccss/2017/03/ sindicalizacion-docente.html

Plan del Buen Vivir (2016). www.planv.com.ec. Recuperado el 12 de noviembre de 2019 de https://www.planv.com.ec/historias/politica/el-reporte-sobre-la-censura-quefue-censurado-48-horas

Posso, C. (2014). El retorno de Ulises. Estado y participación política: conflicto UNE/gobierno1. Quito: FLACSO. Retrieved from. Recuperado el 18 de novimebre de 2019 de http://repositorio. flacsoandes.edu.ec/bitstream/10469/7721/7/TFLACSO-2014CPPC.pdf

Rojas, F., Aguilar, V., \& Piedra, J. (2018). Problemas de la Educación (Primera ed.). Quito: EDICIEM.

Sánchez, H. (2016). Nexos. Recuperado el 16 de julio de 2019 de https://educacion.nexos.com.mx/?p=338

Santos, T. (2018). Retrieved from. Recuperado el 9 de marzo de 2019 de www.vistazo.com: https://www.vistazo.com/seccion/pais/actualidad-nacional/quienes-son-losresponsables-de-los-casos-de-abuso

Terachi, A. (2012). El Neoliberalismo y Bienestar Docente: Un Estudio Comparado de las Condiciones Laborales Docentes en el Sistema Escolar Municipal y Particular Subvencionado. Santiago-Chile: Independent Study Project (ISP) Collection. 1341. 
Torres, R. (2009). Recuperado el 15 de julio de 2019 de evaluaciondocenteecuador.blogspot.com: http://evaluaciondocenteecuador.blogspot.com/2009/07/la-situacion-actualresumen-15-julio.html

UNESCO (2015). Declaración de Incheon y Marco de Acción para la realización del Objetivo de Desarrollo Sostenible 4. UNESCO. Incheon : UNESCO. Recuperado el 13 de julio de 2019 de https://unesdoc.unesco.org/ark:/48223/pf0000245656_spa

Unión Nacional de Educadores. (2015). Idea Network. Retrieved from Idea Network. Recuperado el 8 de septiembre de 2019 de http://idea-network.ca/wpcontent/uploads/2015/09/Seguridad-Social-del-Magisterio-Fiscal-delEcuador.pdf

Vargas-Meza, S. (2016). Red SEPA. Recuperado el 12 de septiembre de 2019 de http://es.idea-network.ca/investigaciones/la-decada-perdida-en-educacion

Yánez, A. (2014). El Plan Decenal de Educación y el enfoque de Derechos Humanos a través del presupuesto público. Lupa Fiscal. Quito: Grupo FARO. Recuperado el 15 de septiembre de 2019 de http://www.reducaal.net/files/observatorio/estudios/lupa_fiscal.pdf

Zabala-Egas, J. (2011). Teoría de la seguridad jurídica. Yuris Dictio Revista del Derecho, 12(14), 13-18.

Zibell, M. (2017). Tras 10 años de gobierno, además de un Ecuador dividido, ¿qué más deja Rafael Correa? BBC. Recuperado el 12 de julio de 2019 de https://www.bbc.com/mundo/noticias-america-latina-38980926 


\section{Autores}

OSWALDO HARO-JÁCOME Doctor PhD. en Investigación Educativa obtenido en la Universidad de Alicante-España; Magister en Educación; Doctor en Investigación Socioeducativa; Licenciado en Filosofía y Ciencias Socioeconómicas; Profesor Normalista.

Actualmente, es docente titular de la Universidad Central del Ecuador en la Carrera de Pedagogía de la Historia y las Ciencias Sociales de la Universidad Central del Ecuador; Exdirector del Instituto Superior de Extensión Universitaria; director de la Carrera Plurilingüe; Ex-Docente titular de la Universidad de las Fuerzas Armadas ESPE; Ex-Docente Colegio Municipal Sebastián de Benalcázar y Ex-Vicerrector de la Unidad Educativa Municipal Eugenio Espejo.

ANA CHAMORRO-MORALES Licenciada en Ciencias de la Educación. Mención Ciencias Sociales de la Universidad Central del Ecuador. 